\title{
Is there an association between shift work and having a metabolic syndrome? Results from a population based study of 27485 people
}

\author{
B Karlsson, A Knutsson, B Lindahl
}

\begin{abstract}
Objectives-To explore how metabolic risk factors for cardiovascular disease (CVD) differ between shift workers and day workers in a defined population. Shift work has been associated with an increased risk of CVD. Risk factors and causal pathways for this association are only partly known.

Methods-A working population of 27485 people from the Västerbotten intervention program (VIP) has been analysed. Cross sectional data, including blood sampling and questionnaires were collected in a
\end{abstract} health survey.

Results-Obesity was more prevalent among shift workers in all age strata of women, but only in two out of four age groups in men. Increased triglycerides $(>1.7 \mathrm{mmol} / \mathrm{l})$ were more common among two age groups of shift working women but not among men. Low concentrations of high density lipoprotein (HDL) cholesterol (men<0.9 and women $<1.0 \mathrm{mmol} / \mathrm{l}$ ) were present in the youngest age group of shift workers in both men and women. Impaired glucose tolerance was more often found among 60 year old women shift workers. Obesity and high triglycerides persisted as risk factors in shift working men and women after adjusting for age and socioeconomic factors, with an OR of $\mathbf{1 . 4}$ for obesity and $\mathbf{1 . 1}$ for high triglyceride concentrations. The relative risks for women working shifts versus days with one, two, and three metabolic variables were $1.06,1.20$, and 1.71 , respectively. The corresponding relative risks for men were $0.99,1.30$, and 1.63 , respectively.

Conclusions-In this study, obesity, high triglycerides, and low concentrations of HDL cholesterol seem to cluster together more often in shift workers than in day workers, which might indicate an association between shift work and the metabolic syndrome.

(Occup Environ Med 2001;58:747-752)

Keywords: shift work; metabolic variables; coronary heart disease

Shift work is associated with coronary heart disease (CHD). ${ }^{1}$ Different mechanisms for this association have been discussed. One model suggests three independent pathways to disease: (a) a mismatch of circadian rhythms, (b)
Main messages

- Shift work could induce increased body mass index.

- Shift work could induce disturbances in serum lipids.

Policy implications

- In health examinations of shift workers should examination of body mass index and serum lipids, especially triglycerides and HDL cholesterol be considered?

behavioural changes, and (c) social disturbances. $^{2}$ Much of the research has been focused on lifestyle factors but recent findings indicate that metabolic disturbances also could be the result of an explicit disruption of circadian rhythmicity. An experimental study by Hampton et al showed that the postprandial glucose concentrations were higher after a meal when the circadian rhythm was phase shifted. A more complex diurnal metabolic regulation has also been suggested involving the pattern of sleep debt, indicating that the quality and duration of sleep could impact on metabolic and endocrine function. ${ }^{45}$ Epidemiological studies have also shown that shift work could lead to acute metabolic disturbances. Theorell and Akerstedt ${ }^{6}$ showed that night work led to changes in the concentrations of serum glucose and serum lipids that returned to normal upon return to day work. Other studies have reported increased concentrations of serum triglycerides in shift workers. ${ }^{1}$

The findings on disturbances in glucose and serum lipids raises the question whether shift work could induce insulin resistance-a lowered sensitivity in muscle, liver and fat cells to the actions of insulin - which is the underlying cause for the metabolic syndrome. The disturbances comprising the metabolic syndrome are obesity (especially abdominal fat accumulation), dyslipidaemia with high triglycerides and

Table 1 Distribution of participants (classification according to age and work schedule)

\begin{tabular}{lrlrllll}
\hline & \multicolumn{2}{c}{ Women } & & \multicolumn{2}{c}{ Men } & & \\
\cline { 2 - 3 } Age $(y)$ & Shift & Day & & Shift & Day & \\
\hline 30 & 971 & 1309 & & 763 & 1422 & \\
40 & 1497 & 3180 & & 1161 & 3002 & \\
50 & 1301 & 3499 & & 944 & 3401 & \\
60 & 863 & 1869 & & 409 & 1894 & \\
Total numbers & 4632 & 9857 & & 3277 & 9719 & 27485 \\
\hline
\end{tabular}




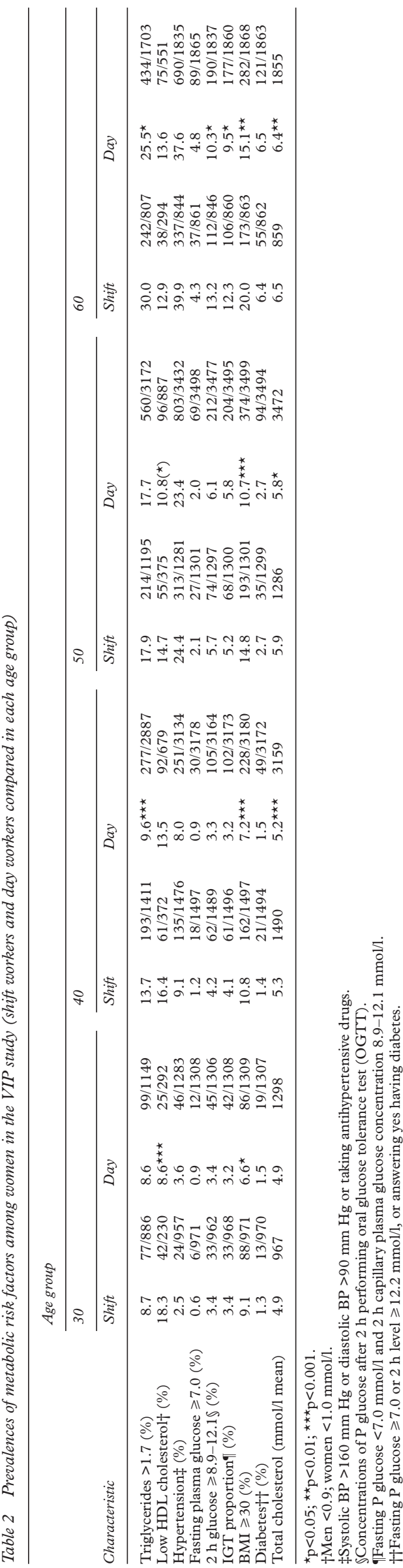

low high density lipoprotein (HDL) cholesterol concentrations, hypertension, and a low fibrinolytic activity. ${ }^{7}$ Often the syndrome includes impaired glucose tolerance. Metabolic syndrome is a common disorder. The prevalence in the north of Sweden is $17 \%$ among men. ${ }^{8}$ There is strong evidence showing that the metabolic syndrome is a risk factor for CHD. ${ }^{9}$ If shift work increases the risk of metabolic syndrome, this could be a possible link, explaining the association between shift work and CHD. The aim of the present epidemiological study was to investigate whether shift work is associated with metabolic disturbances, hypertension and impaired glucose tolerance, which all are parts of the metabolic syndrome.

\section{Methods}

STUDY POPULATION

The Västerbotten intervention programme is an ongoing programme aimed at preventing cardiovascular disease and diabetes in the county of Västerbotten in the north of Sweden.

As a part of this programme all men and women have been invited to a health survey at the age of 30, 40, 50, and 60 years. Since 1985 about 80000 subjects have been invited. The participation rate over several years in Västerbotten has varied between $50 \%$ and $60 \%$ of eligible people. During the period 1992-7, a total of 39977 health examinations were accomplished within the programme. People with missing or incorrect data in the main variables of this study (body weight, height, fasting glucose, and 2 hour glucose) were excluded $(n=3189)$. Also, only subjects currently in permanent work, temporary work, or self employed at the time of health examination were to be included in the study. A total of 27485 people fulfilled these criteria and comprised the present analysis (table 1 ).

\section{DATA COLLECTION}

A total of 48 examination teams were used in the sampling procedure. Only four teams conducted less than 100 health surveys. All participants in the study filled out a questionnaire with questions about working conditions, smoking habits, diet, and level of physical activity.

Shift workers were defined as answering yes to the question: "do you have shift work, or do you work during weekends?" Blood pressure was measured in the supine position after 5 minutes rest.

Hypertension was defined as having a systolic blood pressure above $160 \mathrm{~mm} \mathrm{Hg}$ or a diastolic blood pressure of more than $90 \mathrm{~mm}$ $\mathrm{Hg}$ or answering yes about being on antihypertensive medication. Body weight was measured in light indoor clothing and recorded to the nearest kg. Height was measured to the nearest centimetre without shoes. Body mass index (BMI) was calculated as weight (kg) divided by height squared $\left(\mathrm{m}^{2}\right)$. Those with a BMI of 30 or more were classified as obese.

A simplified oral glucose tolerance test was performed on all participants according to the World Health Organisation (WHO) standard, 


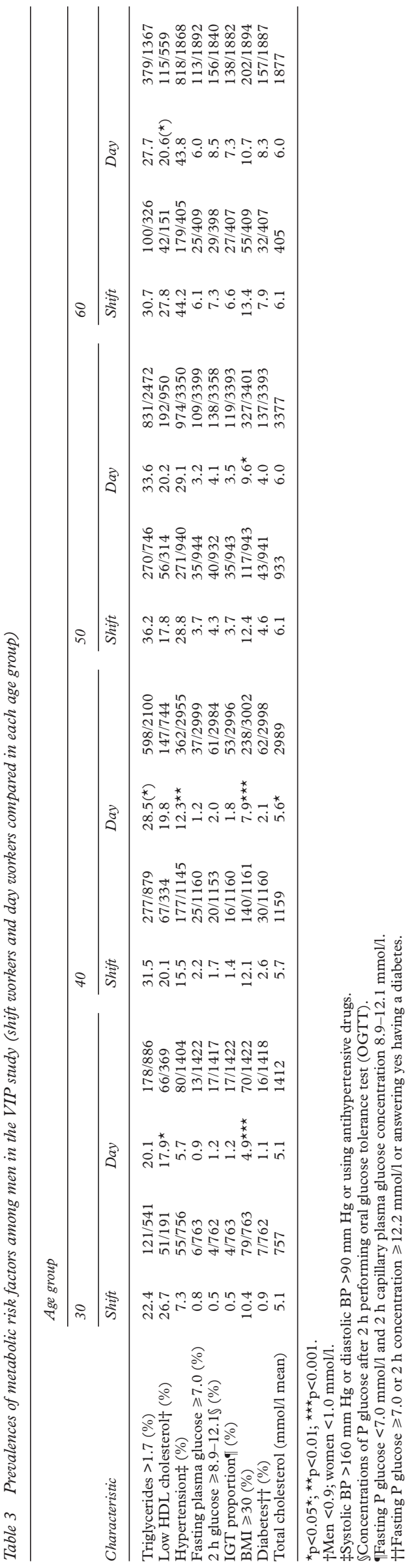

using a $75 \mathrm{~g}$ anhydrous glucose load and measuring plasma glucose after 2 hours. ${ }^{10}$ All stimulated ( 2 hour) glucose concentrations were measured on capillary plasma with Reflotron bench top analysers (Boehringer Mannheim $\mathrm{GmbH}$, Mannheim, Germany). As 2 hour glucose measurements in capillary plasma yield higher values (on average $1.1 \mathrm{mmol} / \mathrm{l}$ ) than in venous plasma, impaired glucose tolerance has, in agreement with WHO standards, ${ }^{10}$ been defined as a 2 hour plasma glucose of more than or equal to $8.9 \mathrm{mmol} / \mathrm{l}$ and less than 12.2 $\mathrm{mmol} / \mathrm{l}$.

Those who had values equal to or above 12.2 $\mathrm{mmol} / \mathrm{l}$ in their 2 hour plasma glucose, or fasting plasma glucose equal to or above 7.0 $\mathrm{mmol} / \mathrm{l}$, or answered yes to the question about being diabetic, were defined in this study as having diabetes mellitus.

Total cholesterol and triglyceride concentrations were measured at the time of the health survey on fresh fasting plasma by the use of Reflotron bench top analysers, ${ }^{11}$ whereas plasma for measurement of HDL cholesterol was sent to a nearby hospital for analysis. The HDL cholesterol was measured after precipitation of the other lipoproteins with sodium phosphowolframate/magnesium chloride. Sampling for plasma triglyceride and HDL cholesterol concentrations was optional and conducted in $65 \%$ and $26 \%$ of the subjects, respectively.

Triglyceride values $>1.7 \mathrm{mmol} / 1$ and HDL cholesterol $<0.9 \mathrm{mmol} / 1$ in men and $<1.0$ $\mathrm{mmol} / \mathrm{l}$ in women were defined as a metabolic risk.

Duration of education was used as a proxy for socioeconomic situation. Low education was defined as $\leqslant 9$ years, middle as $10-12$ years, and high education as $\geqslant 13$ years of school training.

The research ethics committee at Umeå University approved the study, and the National Computer Data Inspection Board approved the data handling procedures.

STATISTICAL ANALYSIS

The SPSS version 10.0 was used. Pearson's $\chi^{2}$ test and students $t$ test were used for comparing proportions and continuous variables respectively. Multiple logistic regression was used for multivariate analyses. Age adjustment was accomplished with direct standardisation.

\section{Results}

High BMIs were more prevalent in nearly all groups of shift workers irrespective of age and sex (table 2 and 3). Among shift workers low HDL cholesterol concentrations were found in the youngest age groups in both sexes. Triglycerides were higher among shift workers in 40 year old men and women, as well as in 60 year old women. The proportion with impaired glucose tolerance among shift working 60 year old women was significantly higher than among corresponding day working women. The total cholesterol concentration was higher in shift working women in all but the youngest age group. 


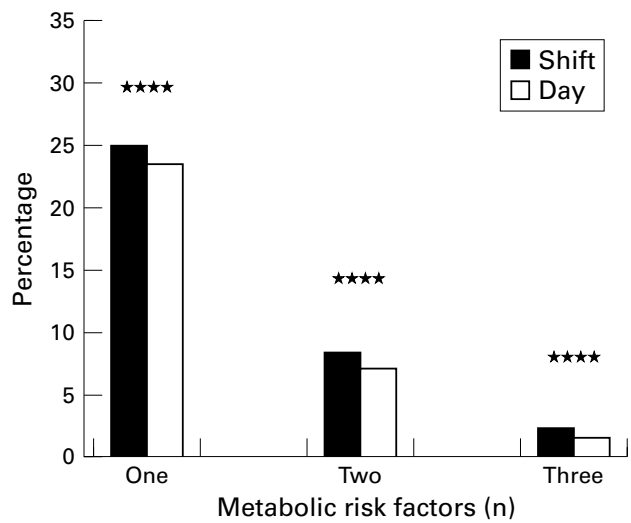

Figure 1 Age adjusted prevalence of number of metabolic risk factors (obesity, hypertension, and high triglycerides) among shift working and day working women. $\star \star * \star * p<0.0001$.

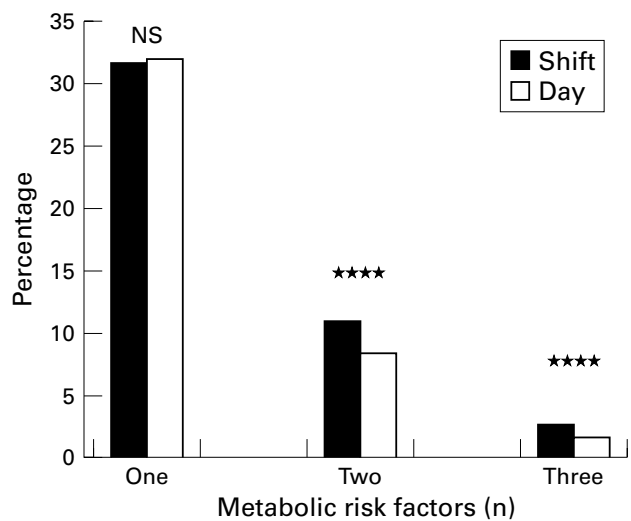

Figure 2 Age adjusted prevalence of number of metabolic risk factors (obesity, hypertension, and high triglycerides) among shift working and day working men. $\star \star \star \star * p<0.0001$.

Hypertension was more common among 40 year old men working shifts than among corresponding day workers.

Having two or more of the three metabolic risk factors (obesity, hypertension, and high triglycerides) simultaneously were, after adjustment for age, significantly more common in both men and women working shifts as illustrated in figures 1 and 2. The relative risks for shift working versus day working women with one, two, and three metabolic variables were $1.06,1.20$, and 1.71 , respectively. The corresponding relative risks for men were 0.99 , 1.30 , and 1.63 , respectively.

In table 4, multiple logistic regression analyses were used to estimate the relative risks of obesity, low HDL cholesterol, and high triglyceride concentrations in shift workers compared with day workers after adjustments were made for age and socioeconomic situation. Increased odds ratios were found for both women and men who worked shifts for BMI and high triglyceride concentrations and this risk increase persisted after adjusting for both age and socioeconomic factors. In women, the crude relative risk for low HDL cholesterol was also significantly increased and persisted after adjusting for age and socioeconomic factors (table 4).

\section{Discussion}

This study showed that obesity was more common in shift workers than in day workers among both men and women. This finding persisted after adjustment was made for age and socioeconomic status. A recent review article summarising previous studies have yielded inconsistent results. ${ }^{1}$ Our results are in agreement with the results in two earlier cohort studies on nurses. ${ }^{12}{ }^{13}$ Furthermore, a Danish cohort study on men aged 40-59 years also found an association between shift work and increased body weight after controlling for socioeconomic factors. ${ }^{14}$ However, Nakamura et $a l^{15}$ did not find any differences in body weight comparing day workers and shift workers, but workers in a three shift rotation had increased abdominal to hip ratio, indicating a higher proportion of central obesity among shift workers. A possible explanation for this could be insufficient adjustment for possible confounding variables-for example, socioeconomic factors. Another possibility is that the duration of follow up could influence the change of body weight as suggested by van Amelsvoort. ${ }^{16}$

He found that the initial reaction when a person starts to work shifts could be a weight decline, but the reaction in the long run could be a weight gain. Taken together, inconsistent results from previous studies could also be due to different durations of follow up.

Increased concentrations of triglycerides were also more commonly reported in shift workers. In a recent review article, increased concentrations of triglycerides among shift workers compared with day workers were reported in four out of 12 studies. ${ }^{1}$ One reason for the inconsistencies could be the large variation of circadian rhythm for triglycerides and that the individual blood samples were measured at different times. ${ }^{17}$

Low HDL cholesterol is associated with an increased risk of heart disease. ${ }^{7}$ In the present study low HDL cholesterol was found among

Table 4 Relative risk of obesity, low HDL cholesterol and high triglycerides associated with shift work (results of multiple logistic regression)

\begin{tabular}{|c|c|c|c|c|c|c|c|c|c|c|c|c|}
\hline \multirow[b]{3}{*}{ Predictor } & \multicolumn{4}{|c|}{ Relative risk of high $B M I$ (obesity) } & \multicolumn{4}{|c|}{ Relative risk of low HDL cholesterol } & \multicolumn{4}{|c|}{ Relative risk of high triglycerides } \\
\hline & \multicolumn{2}{|c|}{ Women } & \multicolumn{2}{|l|}{ Men } & \multicolumn{2}{|c|}{ Women } & \multicolumn{2}{|l|}{ Men } & \multicolumn{2}{|c|}{ Women } & \multicolumn{2}{|l|}{ Men } \\
\hline & $O R^{\star}$ & $95 \% C I$ & $O R^{\star}$ & $95 \% C I$ & $O R^{\star}$ & $95 \% C I$ & $O R^{*}$ & $95 \% C I$ & $O R^{\star}$ & $95 \% C I$ & $O R^{\star}$ & $95 \% C I$ \\
\hline Shift workt & 1.41 & 1.26 to 1.57 & 1.44 & 1.27 to 1.63 & 1.34 & 1.10 to 1.63 & 1.13 & 0.94 to 1.35 & 1.12 & 1.01 to 1.23 & 1.09 & 0.98 to 1.20 \\
\hline Shift work $\ddagger$ & 1.47 & 1.31 to 1.63 & 1.52 & 1.34 to 1.73 & 1.34 & 1.10 to 1.63 & 1.14 & 0.95 to 1.36 & 1.19 & 1.08 to 1.32 & 1.14 & 1.03 to 1.26 \\
\hline Shift work\$ & 1.39 & 1.25 to 1.55 & 1.44 & 1.27 to 1.64 & 1.26 & 1.03 to 1.53 & 1.15 & 0.96 to 1.38 & 1.13 & 1.02 to 1.25 & 1.12 & 1.01 to 1.24 \\
\hline
\end{tabular}

^Odds ratio obtained through multiple logistic regression.

tCrude odds ratio.

$\ddagger$ Odds ratio adjusted for age.

SOdds ratio adjusted for age and socioeconomic group. 
shift workers in the youngest groups of both sexes. In women, the risk of having low HDL cholesterol persisted after adjustment for age and socioeconomic factors. This finding is new as earlier studies have not confirmed a lower HDL cholesterol concentration among shift workers. ${ }^{18-20}$ Normally, HDL cholesterol is at its lowest in the morning, but this may not always be the case as the HDL cholesterol is also known to vary considerably within and between people. ${ }^{17}$ This may be a confounding factor especially when combined with difficulty in measuring shift exposure accurately.

We found no difference in the prevalence of hypertension when comparing shift workers and day workers. These results are consistent with previous studies. ${ }^{1}$

The prevalence of subjects with impaired glucose tolerance was higher among women than men. In the oldest age group of women, impaired glucose tolerance was more common in shift workers than in day workers. One previous study has considered the issue of glucose intolerance among male factory workers, but this study did not report any data of glucose intolerance relative to shift work. ${ }^{21}$

In our study, there was no difference in the prevalence of diabetes mellitus between day workers and shift workers. However, Kawachi et $a l^{13}$ found a clear relation between duration of shift work and diabetes in a cohort study of 79109 female nurses. Mikuni et $a l^{21}$ reported a significantly higher prevalence of diabetes among people working a three shift rotation than among day workers. In an Austrian study comparing day workers and shift workers the morbidity of endocrine and metabolic diseases was increased especially in old shift workers. Subjects with considerable previous exposure to shift work had higher morbidity of endocrine and metabolic disease than day workers, but the prevalence of diabetes was not specifically reported. ${ }^{22}$

Our results showed no difference in prevalence of diabetes between shift workers and day workers. This could be due to the study design. Cross sectional studies have a tendency to underestimate chronic diseases-for example, cardiovascular disease and diabetes due to selection effects. Shift workers who have chronic cardiovascular or metabolic diseases are often transferred to day work.

A limitation of the study is the definition of exposure to shift work. The participants were defined as shift or day workers after answering yes or no to one single question in the questionnaire:"do you have shift work or weekend work?" This question is rather weak and imprecise. It does not bring any information about day to day pattern of shift work, frequency of night work, type of rotation, or duration of shift work. Against this it could be argued that the broad definition does not introduce bias in the results, only a possible underestimation of the risk estimates. Previous epidemiological research has often used the broad definition to describe working hours other than regular work, or a work schedule which includes abnormal working hours. ${ }^{23}$
Despite a broad definition significant associations between exposure to shift work and negative health outcomes have been shown, for example in the study by Tenkanen et al. ${ }^{24} \mathrm{~A}$ reason for this could be that we are dealing with different, but parallel, mechanisms linking shift work to disease. One mechanism could be a direct impact of the disturbance of circadian rhythm associated with shift work. Another could be a stress reaction due to the disruption of a normal social life. ${ }^{2}$

The main strengths of this study are its power due to many observations and that we have had access to socioeconomic variables. We must remember that low socioeconomic status is a potential confounder when studying the associations between shift work and diabetes. The social selection bias of the participants in the Västerbotten intervention programme study has earlier been examined and found to be marginal. Weinehall et $a l^{25}$ examined the potential socioeconomic differences between participants and non-participants through a record linkage between all workers invited to the 1992 and 1993 health surveys and the 1990 population and housing census in Sweden. Unemployment, low income, and younger age tended to be associated with a lower preference to participate.

Is it possible from our data to draw the conclusion that shift work is associated with the metabolic syndrome? Recently, the metabolic syndrome was defined as having a disturbance in the glucose-insulin axis, (type 2 diabetes, impaired glucose tolerance, or insulin resistance) in combination with two of the following criteria; high triglycerides or low HDL cholesterol, increased blood pressure, central obesity, or $\mathrm{BMI} \geqslant 30$, and microalbuminuria. ${ }^{26}$

In the present study it was not possible to estimate insulin resistance. The consequence of this was that an assessment of the glucoseinsulin axis could be made in only a few participants - namely, those having impaired glucose tolerance or diabetes. This severely limited our chance to use the new definition of the metabolic syndrome on the whole study population. However, our study does show that the important metabolic risk variables of obesity, raised triglyceride concentrations, and low HDL cholesterol concentrations are more common in shift workers than in day workers. Furthermore, these metabolic risk variables, characteristic of the metabolic syndrome, cluster together in shift workers. This may indicate that shift work is associated with the metabolic syndrome.

This study was supported by the Västerbotten County Council and the Swedish Public Health Institute. We thank Lars Weinehall for valuable contributions.

1 Bøggild H, Knutsson A. Shiftwork, risk factors and cardiovascular disease. Scand $\mathcal{f}$ Work Environ Health 1999;25:8599.

2 Knutsson A, Bøggild H. Shiftwork and cardiovascular disease: review of disease mechanisms. Rev Environ Health 2000;15:359-72.

3 Hampton SM, Morgan LM, Lawrance N, et al. Postprandial hormone and metabolic responses in simulated shiftwork. $\mathcal{F}$ Endocrinol 1996;151:257-67.

4 Spiegel K, Leproult R, VanCauter E. Impact of sleep debt on metabolic and endocrine function. Lancet 1999;354: on metabolic 
5 Scheen J, Van Cauter E. The roles of time of day and sleep quality in modulating glucose regulation: clinical implicaquality in modulating glucose regu
tions. Horm Res 1998;49:191-201.

6 Theorell T, Åkerstedt T. Day and night work: changes in cholesterol, uric acid, glucose, and potassium in serum and in circadian patterns of urinary cathecolamine excretion. Acta Med Scand 1976;200:47-53.

7 DeFronzo R, Ferrannini E. Insulin resistance. A multifaceted syndrome responsible for NIDDM, obesity, hypertension, dyslipidemia, and atherosclerotic cardiovascular disease. Diabetes Care 1991;14:173-94

8 Lindahl B, Asplund K, Hallmans G. High serum insulin, insulin resistance and their associations with cardiovascular risk factors. The northern Sweden population study. $\mathcal{F}$ Intern Med 1993;234:263-70.

9 Haffner S. Epidemiology of insulin resistance and its relation to coronary artery disease. Am 7 Cardiol 1999;84: $11 \mathrm{~J}-14 \mathrm{~J}$.

10 World Health Organisation. Diabetes mellitus. Report of a WHO study group. Geneva: World Health Organization, WHO study group. Geneva: World He

11 von Schenk $\mathrm{H}$, Treichl L, Tilling B, Laboratory and field evaluation of three desktop instruments for assay of cholesevaluation of three desktop instruments for assay of
terol and triglyceride. Clin Chem 1987;33:1230-2

12 Niedhammer I, Lert F, Marne M-J. Prevalence of overweight and weight gain in relation to night work in nurses' cohort. Int f Obes Relat Metab Disord 1996;20:62533.

13 Kawachi I, Colditz G, Stampfer M, et al. Prospective study of shiftwork and risk of coronary heart disease in women. Circulation 1995;92:3178-82.

14 Bøggild H, Suadicani P, Hein H, et al. Shiftwork, social class and ischaemic heart disease in middle aged and elderly men; a 22 year follow up in the Copenhagen male study. Occup Environ Med 1999;56:640-5.
15 Nakamura K, Shimai S, Kikuchi S, et al. Shiftwork and risk factors for coronary heart disease in Japanese blue-collar factors for coronary heart disease in Japanese blue-collar Occup Med 1997; 47:142-6.

16 van Amelsvoort L. Cardiovascular risk profile in shift workers [thesis]. Wageningen: Wageningen University, 2000

17 Rivera-Col A, Funtes-Arderiu L, Diez-Noguera A. Circadian rhythmic variation in serum concentrations of clinically important lipids. Clin Chem 1994;40:1549-53.

18 Knutsson A, Åkerstedt T, Jonsson BJ. Prevalence of risk factors for coronary artery disease among day and shift workers. Scand $\mathcal{F}$ Work Environ Health 1988;14:317-21.

19 Romon M, Nuttens M-C, Fievet C, et al. Increased triglyceride levels in shift workers. Am f Med 1992;93:259-62.

20 Costa G, Betta A, Uber D, et al. Estimate of coronary risk in a group of Italian shiftworkers. In: Costa G, Cesana G, Kogi K, et al, eds. Shiftwork: health, sleep and performance. Frankfurt am Main: Peter Lang, 1990:363-9.

21 Mikuni E, Ohoshi T, Hayashi K, et al. Glucose intolerance in an employed population. Tohoku f Exp Med 1983; 141(suppl):251-6.

22 Koller M. Health risks related to shift work. Int Arch Occup Environ Health 1983;53:59-75.

23 Taylor P, Pocock S. Mortality of shift and day workers 1956-68. Br F Ind Med 1972;29:201-7.

24 Tenkanen L, Sjöblom T, Kalimo R, et al. Shiftwork, occupation and coronary heart disease over 6 years follow up in the Helsinki Heart Study. Scand 7 Work Environ Health 1997;23:257-65.

25 Weinehall L, Hallgren CG, Westman G, et al. Reduction of selection bias in primary prevention of cardiovascular disease through involvement of primary health care. Scand f Prim Health Care 1998;16:171-6.

26 Groop L. Genetic and metabolic heterogeneity of diabetes. International Diabetes Monitor 2000;12:1-6.

\section{Vancouver style}

All manuscripts submitted to Occup Environ Med should conform to the uniform requirements for manuscripts submitted to biomedical journals (known as the Vancouver style.

Occup Environ Med, together with many other international biomedical journals, has agreed to accept articles prepared in accordance with the Vancouver style. The style (described in full in the $\mathcal{F} A M A[1]$ ) is intended to standardise requirements for authors, and is the same as in this issue.

References should be numbered consecutively in the order in which they are first mentioned in the text by Arabic numerals on the line in square brackets on each occasion the reference is cited (Manson[1] confirmed other reports[2][3][4][5]). In future references to papers submitted to Occup Environ Med should include: the names of all authors if there are three or less or, if there are more, the first three followed by et al; the title of journal articles or book chapters; the titles of journals abbreviated according to the style of Index Medicus; and the first and final page numbers of the article or chapter. Titles not in Index Medicus should be given in full.

Examples of common forms of references are:

1 International Committee of Medical Journal Editors. Uniform requirements for manuscripts submitted to biomed journals. FAMA 1993;269:2282-6.

2 Soter NA, Wasserman SI, Austen KF. Cold urticaria: release into the circulation of histmaine and eosinophil chemotactic factor of anaphylaxis during cold challenge. N Engl F Med 1976;294:687-90.

3 Weinstein L, Swartz MN. Pathogenic properties of invading micro-organisms. In: Sodeman WA Jr, Sodeman WA, eds. Pathologic physiology, mechanisms of disease. Philadelphia: W B Saunders, 1974:457-72. 